\title{
O PORTFÓLIO COMO UMA ESTRATÉGIA DE APRENDIZAGEM NA FORMAÇÃO DOS PROFISSIONAIS DE SAÚDE
}

\author{
EL PORTFOLIO COMO UNA ESTRATEGIA DE APRENDIZAJE EN LA \\ FORMACIÓN DE LOS PROFESIONALES DE SALUD
}

\section{THE PORTFOLIO AS A LEARNING STRATEGY IN THE TRAINING OF HEALTH PROFESSIONALS}

\author{
Marta FUENTES-ROJAS ${ }^{1}$
}

RESUMO: O objetivo foi utilizar o portfólio como uma estratégia de ensino para promover a participação e a reflexão de temáticas da área da saúde coletiva e da educação em saúde. Permite desenvolver no aluno habilidades reflexivas e motiva a busca de novas formas de apreender. O professor vai além da verificação de aprendizagem, solicita maior atenção, oferece novas indagações e aponta prioridades na aprendizagem. Participaram dessa estratégia 120 alunos de duas disciplinas da saúde coletiva. Observou-se no início da atividade resistência dos alunos ao exigir maior participação, envolvimento, criatividade e responsabilidade. Em relação à contribuição para a área, o portfólio possibilitou o seu exercício, o envolvimento de todos, a avaliação de todo o processo, assim como ajudou a desenvolver habilidades de organização, cuidado com os detalhes, rever na pratica a convivência com o grupo e a distribuição de responsabilidades.

PALAVRAS-CHAVE: Metodologia participativa. Ensino superior. Estratégia pedagógica. Portfólio.

RESUMEN: El objetivo fue utilizar el portafolio como una estrategia de enseñanza para promover la participación y la reflexión de temáticas del área de la salud colectiva y de la educación en salud. Permite desarrollar en el alumno habilidades reflexivas y motiva la búsqueda de nuevas formas de aprehender. El profesor va más allá de la verificación de aprendizaje, solicita mayor atención, ofrece nuevas indagaciones y apunta prioridades en el aprendizaje. Participaron de esta estrategia 120 alumnos de dos disciplinas de la salud colectiva. Se observó al inicio de la actividad resistencia de los alumnos al exigir mayor participación, implicación, creatividad y responsabilidad. En cuanto a la contribución al área, el portafolio posibilitó su ejercicio, la participación de todos, la evaluación de todo el proceso, así como ayudó a desarrollar habilidades de organización, cuidado con los detalles, revisar en la práctica la convivencia con el grupo y la distribución de responsabilidades.

${ }^{1}$ Universidade Estadual de Campinas (Unicamp), Campinas - SP - Brasil. Professora pesquisadora da Faculdade de Ciências Aplicadas da Universidade Estadual de Campinas. E-mail: marta.fuentes@fca.unicamp.br 
PALABRAS-CLAVE: Metodología participativa. Enseñanza superior. Estrategia pedagógica. Portfolio.

ABSTRACT: The objective was to use the portfolio as a teaching strategy to promote the participation and reflection of issues in the area of collective health and health education. It allows students to develop reflexive skills, motivating the search for new ways to learn. The teacher goes beyond the learning check, requests more attention, offers new questions and points out priorities in learning. Participated in this strategy, 120 students from two collective health disciplines. It was observed at the beginning of the activity, resistance of the students when demanding greater participation, involvement, creativity and responsibility. Regarding the contribution to the area, the portfolio made possible its exercise, the involvement of all, the evaluation of the whole process, as well as helped to develop organizational skills, care with the details, to review in practice the coexistence with the group and the distribution of responsibilities.

KEYWORDS: Participatory methodology. Higher education. Pedagogical strategy. Portfolio.

\section{Introdução}

Pensar na prática do professor, na área da saúde, tem sido preocupação de alguns estudos. Segundo Castanho (2002), ser professor é uma construção de maneiras de ser e de estar: a forma de como somos professor depende daquilo que somos como indivíduos quando ensinamos. A isto, se soma nossa concepção de conhecimento, de ensino e de avaliação, assim como se evidência a organização do trabalho em sala de aula e inclusive a inserção da nossa prática pedagógica no plano político-pedagógico da própria instituição.

Muito se fala sobre inovação na educação, sobre caraterísticas inovadoras na sala de aula. No estudo realizado por Veiga et al (2000 apud Castanho 2002), observaram caraterísticas inovadoras nas atividades de ensino e afirmam que alguns professores fazem o movimento da inovação de forma intuitiva e tímida, procurando respeitar a singularidade de cada aluno, promovendo a participação deste através de atividades como trabalho em grupo, atividades coletivas, entre outras. Além disto, incentivam à pesquisa, mostram preocupação pela interdisciplinaridade, vão além do ensino dos conteúdos específicos e buscam fazer discussões mais humanas. Os autores apontam, no entanto, que falta nestas mudanças fundamentação teórica que melhore realmente o ensino. 
Vários estudos mostram que experiências inovadoras em sala de aula estão acontecendo, mesmo que timidamente. As mudanças que já acontecem, embora pequenas, mostram que os professores estão reestruturando suas concepções e investindo em meios diferenciados de ensinar e aprender (BORGES; TAUCHEN, 2012). Isto é, cada docente produz sua própria forma de ser professor de acordo com as demandas surgidas na sala de aula (CASTANHO, 2002).

Para Masetto (2004), a inovação acontece, mas esta só pode acontecer quando as pessoas se dispõem a aprender, a mudar, a obter novos conhecimentos, alterar seus conceitos, assumir novos comportamentos e atitudes e aderir a novas maneiras de pensar e de agir. Isto significa, complementa o autor, compromisso com a prática educativa, como pano de fundo para a construção de novos conhecimentos, ou seja, é a atividade docente vivenciada e repensada.

Nesse sentido, os estudos destacam que ainda são poucas as reflexões sobre as experiências inovadoras nas instituições universitárias, mesmo assim, existem muitas intenções de mudança.

Diante da fragilidade na formação dos profissionais de saúde para responder às demandas sociais, as instituições têm sido incentivadas a refletir, discutir e buscar formas de transformar o ensino, considerando não só o conteúdo, mas a valorização da equidade, da qualidade, da eficiência e relevância do cuidado em saúde. Formar profissionais de saúde com competências que lhes permitam recuperar a relação humana como a dimensão principal do cuidado, além de oferecer um processo de reelaboração de conhecimentos mais significativos para os alunos (CIRYNO; TORALLESPEREIRA, 2004).

Com o advento da sociedade do conhecimento, da revolução da informação e da exigência da produção de conhecimento, os profissionais de todas as aéreas de conhecimento são afetados, portanto, exige repensar papéis e funções (BEHRENS, 1999). Com isto, a sociedade passa a exigir profissionais que tenham capacidade de tomar decisões, que sejam autônomos, produzam com iniciativa própria, saibam trabalhar em grupo, partilhem suas conquistas e estejam em constante formação. Nesse movimento de mudança, o professor passa a ter um papel fundamental de articulador e mediador entre o conhecimento elaborado e o conhecimento a ser produzido.

Desse modo, formar profissionais para a área da saúde torna-se uma questão relevante devido às características e necessidades da população e à manutenção e efetivação do SUS. Ao mesmo tempo, ministrar disciplinas da área da saúde coletiva 
para novos campos de atuação torna-se um grande desafio quando se trata de áreas onde se valoriza a técnica, a especificidade e pelo fato de não ser um campo de interesse na formação.

Mesmo que o projeto pedagógico do curso promova a formação de profissionais para a área da saúde, na prática, existe uma dificuldade, tanto dos docentes da área especifica, como dos alunos: considerar os conteúdos da Saúde Coletiva relevantes para a formação. Com esta postura, podemos inferir que isto seja produto de uma formação especializada e cujo campo de atuação não contemple novas áreas como o da saúde coletiva ou mesmo o campo das humanidades.

Percebe-se dificuldade e falta de interesse dos alunos em se visualizarem nesse campo, desse modo, o seu envolvimento torna-se um desafio para os docentes envolvidos. Conviver com o desafio de defender a área em todos os espaços, mostrar a importância desta na formação dos estudantes, além de lidar com a falta de motivação do aluno e desvalorização do seu conteúdo na fala dos docentes.

O que foi apontado mostra a necessidade de realizar mudanças nas metodologias e criar novas formas de atingir o estudante nos tempos atuais, considerando que este vive num mundo onde os inúmeros estímulos oferecidos, na maioria das vezes, são mais interessantes que a sala de aula. Neste tempo, o aluno se apresenta impaciente, desinteressado, pouco participativo nas discussões, pouca disposição para a reflexão crítica, deixando de cumprir aquilo que se espera dele.

Uma grande questão surge: como ser um bom professor/educador se não temos alunos que nos questionem, nos motivem para criar e construir juntos, como fazer que estes alunos gerem em nós professores um movimento que nos obrigue a criar novas estratégias metodológicas?

Há algum tempo as metodologias utilizadas na sala de aula tem se mostrado pouco motivadoras e o envolvimento dos estudantes é cada vez menor, por isto, é necessário, ao planejar uma disciplina, considerar alguns pontos importantes se pretendemos trazer inovação para estudantes, com baixa estima e visão de futuro. Entre estes pontos devemos considerar: para quem estamos planejando esta aula, quais experiências foram já vivenciadas na abordagem e motivação destes estudantes, o que eles precisam na sua formação e que mudanças podem ser promovidas neles e no seu entorno social. Formar-se na universidade vai além da técnica, significa formar profissionais com uma bagagem ampla, que possam dar conta das demandas do 
mercado e das demandas sociais envolvidas na sua profissão e na sua formação como pessoas.

Pensar na educação como transformadora de práticas e saberes requer compromisso do educador e de seu aluno. Freire $(2006$; 1998) afirma que para ser capaz de se comprometer, é necessário ser capaz de agir e refletir. E para isto, conforme Rogers (1986; 2001) é importante aceitar que os seres humanos possuem uma potencialidade natural para o aprendizado e quando se lhe oferecem os meios e espaços em que possa se apropriar dele, ele aprende sozinho ou em cooperação com os outros. Para esses autores, não se pode refletir sobre educação sem considerar o próprio homem, num tempo e num espaço.

Quando se oferece ao estudante um ambiente facilitador de aprendizado, "aprender um do outro se torna tão importante como aprender nos livros, [...]" (ROGERS, 1986, p. 195). Nesse contexto de aprendizado, os alunos se tornam merecedores de confiança, e o educador um facilitador que partilha com os alunos as responsabilidades do processo de aprendizagem e procura sempre recursos tanto próprios da sua atitude como da experiência com materiais e metodologias diferenciadas.

Mesmo com alguns movimentos, ainda a educação permanece vertical e unidirecional, o professor ainda é um ser superior e o educando recebe passivamente os conteúdos, mantendo-se depósito do saber do professor que retêm o saber como sendo único e não busca novos saberes por que não é desafiado pelos alunos. (FREIRE, 1998, 2006; ROGERS, 2001). A educação deve levar o aluno a refletir sobre sua realidade, deixando de ser expectador para ser sujeito/ autor da mudança. Para isto, precisam ser oferecidos espaços em que se possam desenvolver habilidades e potencialidades, para intervir e ter a oportunidade de ser, pensar e agir.

Mediante esses pressupostos, utilizamos o portfólio como uma estratégia de ensino, junto com o trabalho em oficinas e metodologias problematizadoras e ativas.

O portfólio é definido por Hernández (1998 apud Rodrigues 2009) como um conjunto de documentos que registram entre outros documentos: notas pessoais, trabalhos pontuais, experiências de aula, relações com outros temas e/ou disciplinas, representações e percepções. Estes documentos se transformam em evidências sobre os conhecimentos construídos, as estratégias utilizadas pelos alunos e a disposição dos participantes para o aprendizado e sua continuidade. 
É um instrumento que permite ao aluno construir seu próprio saber e prática, ultrapassando a reprodução da teoria, possibilita a intervenção na sua realidade produzindo saberes e avaliando suas limitações. Ele é mais do que uma coleção de trabalhos mesmo porque ele promove, ao longo do tempo, uma aprendizagem reflexiva. (VIEIRA; DE SORDI, 2012; RODRIGUES, 2009; RANGEL, 2003).

Como meio reflexivo da aprendizagem permite a avaliação da mesma no processo, na prática. É um conjunto de produções de uma disciplina ou de um trabalho proposto, podendo incluir a história dos alunos, relatórios de pesquisa, reflexões de trabalhos, expectativas sobre o trabalho, autorreflexão e autoavaliação. Chun e Bahia (2009) afirmam que o foco do portfólio é a habilidade reflexiva que favorece o aprendizado efetivo das experiências vivenciadas, contribuindo com a formação de um profissional reflexivo.

De acordo com Sá-Chaves (2000 apud Rodrigues, 2009), o portfólio proporciona o diálogo entre o professor e o aluno, além de contribuir com a avaliação do desempenho. Facilita a reflexão na medida em que o aluno vai tomando consciência do aprender a aprender, traçando objetivos, melhorando sua prática e se desenvolvendo de forma profissional e pessoal, e se tornando parceiro na construção de conhecimento.

Conforme Vieira e De Sordi (2012), no processo de mudança das práticas pedagógicas, no protagonismo dos diferentes atores e na articulação permanente dos processos do trabalho pedagógico, pensar na escola e nos modos de trabalho por meio da reflexão crítica do fazer "no sentido de investigar e avaliar a própria prática e transformá-la na aproximação com o outro e do conhecimento, configurando um novo saber ser, um novo saber fazer, um novo saber conviver, um novo modo de conhecer" (p.3).

Para Villas Boas (2008), o portfólio motiva o aluno à busca por novas formas de apreender, na medida em que observa suas produções, vai revelando suas capacidades e potencialidades. Com essa ferramenta, o professor vai além da verificação de aprendizagem, porque possibilita e incentiva não só ao aluno a mostrar o seu progresso, comunicar e defender sua posição, mas também ao professor na medida em que solicita maior atenção. Assim, o processo se torna parte da sua prática e lhe oferece novas indagações, lhe aponta prioridades na aprendizagem e o leva a manter uma reflexão permanente em relação a todos os atores envolvidos.

Para Tanji e Dantas da Silva (2008), este instrumento permite observar no educando a capacidade de resolver problemas e desenvolver competências especificas, 
por meio dos projetos que propõe e participa, ao mesmo tempo oferece informações sobre o conhecimento e atitudes diante a tarefa. Permite o exercício de criar, registrar, compilar, identificar, analisar criticamente o seu trabalho e selecionar o que é mais relevante, bem como descrever os momentos de aprendizagem que lhe permitem ressignificar seus conhecimentos e refletir sobre sua própria formação. Sendo uma coleção de trabalhos realizados, por ele mesmo, permite que acompanhe seu próprio desenvolvimento.

Alvarenga e Araújo (2006), no estudo sobre a revisão de conceitos básicos para a utilização do portfólio, referenciam vários autores que defendem o seu uso como um instrumento que permite observar tanto o professor quanto o aluno, no processo de desenvolvimento de um trabalho. Esses mesmos autores citam a Crockett (1998), que faz algumas considerações quanto ao uso do portfólio, tais como: o professor deve aprender sobre o instrumento e perceber o que representa para os estudantes elaborá-lo; compreender que existem objetivos e competências a serem atingidos e que podem se modificar no processo; decidir os tipos de evidencia que provam o aprendizado; preparar, informar e auxiliar para que os alunos possam elaborar adequadamente as tarefas propostas; encorajar os alunos a refletir sobre suas habilidades, dificuldades, interesses e experiências, estimulando a criatividade; ser um facilitador; criar oportunidades de socialização; e no arquivamento identificar objetivos, competências, habilidades e conteúdos relacionados com a prática. Igualmente, apresentam indicadores gerais que contribuem com a avaliação do professor, entre estes a organização; a documentação demonstra conhecimento; presença de reflexões; evidencias que demonstrem como se deu o processo; demonstração de conhecimento obtido e aplicação do mesmo; as reflexões como indicadores de aprendizagem.

$\mathrm{Na}$ nossa experiência, o uso do portfólio como estratégia nas disciplinas de Saúde Coletiva; e Educação e Comunicação em Saúde nos levou a várias indagações, que se transformaram em questões-problema e cuja pretensão foi avaliar a efetividade daquela ferramenta como um recurso pedagógico, que contribuirá com a motivação e valorização da área.

\section{Algumas questões-problema}


Uma das questões que levaram a pensar nesta estratégia foi tentar identificar metodologias que permitam que os alunos encontrem na saúde coletiva um campo de trabalho a ser construído e que necessita de profissionais participativos, reflexivos e humanos. Utilizar o portfólio como estratégia trará mudanças no interesse dos alunos? Quais fatores podem ser identificados na experiência dos alunos com o portfólio, como estratégia de aprendizagem? Conforme já testamos com outras metodologias participativas, o portfólio pode além de ser um instrumento de registro, pode mostrar para o aluno o processo integral da sua atuação na disciplina. Quais contribuições podem ser identificadas no uso do portfólio como estratégia didático-pedagógica na disciplina de Saúde Coletiva e Educação e Comunicação em Saúde em estudantes dos cursos de Nutrição e Ciências do Esporte? De que modo o portfólio pode se tornar um instrumento facilitador da formação dos futuros profissionais da saúde? Em que medida o uso do portfólio pode se tornar um instrumento facilitador da aprendizagem do trabalho?

\section{Objetivos}

$\checkmark$ Identificar contribuições do portfólio como estratégia didático-pedagógica em sala de aula.

$\checkmark$ Compreender, descrever e analisar o uso de portfólio na sala de aula como estratégia de formação e reflexão dos estudantes da faculdade.

$\checkmark$ Conhecer e analisar as percepções dos alunos em relação às contribuições do portfólio para sua formação como futuros profissionais da saúde.

$\checkmark$ Identificar dificuldades e facilidades na construção do portfólio.

\section{Metodologia}

Os alunos foram orientados desde o início das disciplinas para a elaboração do trabalho final do curso, cujo produto seria o portfólio. Para tanto, foram disponibilizadas orientações para a elaboração do portfólio e oferecido supervisão no final das aulas e se estabeleceu para cada disciplina um trabalho de final de curso que foi elaborado e desenvolvido no percurso de 15 encontros. No plano de desenvolvimento das 
disciplinas foram especificadas as atividades, os temas e as práticas a serem desenvolvidas na sala de aula e que deveriam ser registradas no instrumento, acompanhadas de uma reflexão individual. Em cada encontro, foi trabalhado um conceito por meio de oficinas e ou metodologias diferenciadas que promoveram e mantiveram a motivação e o interesse dos alunos pelos conteúdos básicos da Saúde Coletiva e das práticas de Educação em Saúde.

Dadas as características das turmas e o grande número de alunos por turma, não foi viável a avaliação e análise dos portfólios individuais. Foi tomada como estratégia a realização de um portfólio por grupo o qual deveria conter as contribuições individuais dos membros do grupo, assim como aquelas construídas coletivamente.

O método foi aplicado em duas disciplinas: Saúde Coletiva e; Educação e Comunicação em Saúde, das quais participaram alunos do curso de Nutrição e do curso de Ciências do Esporte. Participaram em média 60 alunos por disciplina para um total de 120 alunos, os quais foram divididos em 12 grupos por turma, para um total de 24 portfólios. Foram oferecidos aos alunos horários de supervisão no desenvolvimento do trabalho, com o objetivo de orientá-los na visita do território na disciplina de Saúde Coletiva e no trabalho de intervenção na disciplina de Educação e Comunicação em Saúde e na elaboração do portfólio. Quanto à realização do portfólio, os alunos tiveram certa liberdade para sua elaboração: um dos objetivos foi dar a possibilidade para que utilizassem a criatividade e pudessem construir juntos não só o portfólio, mas reflexões em relação ao seu papel dentro da sua própria formação.

No final do curso, os alunos das duas disciplinas apresentaram ao público da faculdade seus trabalhos do território (27 de novembro de 2013) e os projetos de intervenção nas comunidades visitadas (18 de novembro de 2013), assim como os portfólios, como trabalho final da disciplina. Foi solicitado aos alunos, através de um instrumento com perguntas abertas, colocar suas impressões sobre o processo de construção do portfólio e da disciplina como um todo.

\section{Resultados e discussão}

Introduzir o portfólio nas disciplinas foi interessante porque permitiu acompanhar o processo de desenvolvimento e envolvimento dos alunos. Igualmente foi possível observar a reação dos alunos diante de metodologias diferentes. Assim, 
podemos apontar que, por serem duas turmas, cada uma delas reagiu de forma diferente. No entanto, para as duas, o portfólio foi um instrumento novo, que nunca tinha sido realizado, conforme foi manifestado pela maioria dos alunos. Cabe ainda relatar que no início da proposta poucos se interessaram por saber o que era e como deveria ser feito.

Percebemos que na explicação sobre o portfólio para a maioria dos alunos foi entendido como mais um trabalho final de disciplina, que poderia ser feito no final conforme costume, e os alunos pareciam não estar preocupados com a elaboração do mesmo. Na medida em que foi sendo colocado que deveria aparecer as suas impressões, planejamentos e tudo aquilo que poderia ajudar para desenvolver o trabalho, tanto no território como nas atividades com a população, nos projetos de intervenção, alguns começaram a procurar saber o que fazer e o que seria esse portfólio. Foi oferecida supervisão com a finalidade de orientá-los para a sua elaboração. Nas supervisões, percebíamos como o portfólio ia ganhando forma e identidade de acordo com os membros de cada grupo.

Um portfólio foi colocado como exemplo, elaborado pela professora e a cada encontro foi deixado à disposição para que os alunos o observassem e percebessem mudanças nele, na medida em que aconteciam as atividades a professora colocava suas apreciações, reflexões e conteúdos trabalhados. Foi interessante porque cada vez que se anexava alguma atividade ou algum texto, alguns alunos iam percebendo que havia alguma coisa nova e os motivava a perguntar e comparar com o construído pelo grupo. Aos poucos eles foram criando suas próprias estratégias para dar forma ao portfólio.

Os resultados obtidos com esta atividade foram diversos: desde aqueles portfólios que mostraram pouco interesse dos alunos com a tarefa, até aqueles bastante criativos que mostraram o processo como um todo. No final, apesar das resistências de alguns alunos para atividades novas que de alguma forma os obrigava a refletir, alguns portfólios nos emocionaram, porque retrataram os momentos vivenciados por eles, os alunos se permitiram colocar suas emoções, tanto na atividade como na descrição da mesma, além da compreensão e associação dos conteúdos trabalhados na disciplina. Também foi possível observar a dificuldade de alguns alunos de se colocar e construir junto suas percepções, não conseguir fazer uma reflexão da experiência, nem fazer associação dos conteúdos com a prática e se ater a apresentar um simples relatório. Uma das questões que chamou a atenção e que o portfólio permitiu observar foi a dificuldade que os alunos apresentam ao desenvolver atividades mais participativas que exigem deles maior envolvimento, criatividade e responsabilidade. 
Dos 24 portfólios, dois grupos não conseguiram construí-lo e se limitaram a colocar um relatório sem nenhuma reflexão ou analise, colocando simplesmente cinco folhas dentro de uma pasta, o que mostrou duas coisas, ou não entenderam ou não deram valor à construção do portfólio. Já outros foram descrevendo e se apropriando da atividade a partir do momento da vivencia e, no portfólio, foi possível perceber não só seu crescimento como seu envolvimento e responsabilidade, no trabalho com as comunidades. Outros grupos ficaram receosos de colocar suas impressões por considerar que seriam mal avaliados, mas outros arriscaram e colocaram tudo o que os levou a fazer a atividade e se apropriaram do instrumento, colocando diversos textos e reflexões na medida em que iam desenvolvendo o trabalho e solicitando supervisão em cada etapa do processo.

Cabe apontar que um dos portfólios emocionou pela descrição que foi feita das atividades desenvolvidas com a população e na sala de aula. Este portfólio mostrou emoção, preocupação, paixão com que pode ser realizado um trabalho e como os alunos podem se apaixonar por uma atividade e desenvolvê-la de forma que contribua com sua formação. Assim como também, como uma ação simples pode ajudá-los a encontrar sentido a sua formação e que se efetiva no trabalho com a população.

Dentro das avaliações elaboradas pelos alunos, construir o portfólio foi para a maioria algo novo, no início causou estranheza, receio, apreensão, chatice, preocupação, duvida, surpresa, ansiedade, desanimo, curiosidade, medo, mais um trabalho, diferente, inovador. Mas, aos poucos foram se apropriando e vivenciando diferentes fases, na própria construção. Com isto percebemos a importância de promover espaços onde se possa ser criativo, afetivo, reflexivo e participativo, mesmo que no início apareça a resistência.

No começo fiquei apreensiva por não saber como seria, porém com o tempo e as dúvidas tiradas consegui desenvolve-lo e o portfólio foi fluindo com todas as informações possiveis de tudo o que tínhamos desenvolvido do projeto" A47; "Eu imaginei que seria algo muito chato de se fazer, porque eu nunca tinha feito antes e já supus que iria dar bastante trabalho" A3; "Não gostei, pois deu muito trabalho" A12; "Fiquei um pouco desinteressada em fazer o portfólio, pois tinha muitos trabalhos de outras matérias pra fazer" A50; "Inicialmente achei desnecessário" A16; "Elaboração do portfólio me deu uma reação de surpresa, pois é a primeira disciplina que participa com este modo de ensino A43.

Quanto às dificuldades apontadas, a maior, segundo seus depoimentos, foi colocar a sua opinião sobre o processo do trabalho e se ver como parte do trabalho falando de si e de suas contribuições. Isto talvez, por ser a primeira vez que se pede para 
colocar-se dentro do trabalho, de forma livre sem cobranças de formato acadêmico, conforme sempre foi pedido. Alguns apontaram que este tipo de atividades demanda mais trabalho e maior pesquisa, realizar ele em grupo foi uma dificuldade por ter que refletir sobre o que foi feito e o fato do portfólio solicitar a presença e a participação de todos. Manifestaram também, dificuldade em se reunir e aceitar as ideias dos outros, escrever, o fato não ter feito ele antes, não ter um padrão e ser livre.

Dentro dos pontos positivos, para alguns deles foi ótimo, porque permitiu colocar todas as ideias, refletir, e aprender a organizar as ideias.

O portfólio permite a melhor visualização do conteúdo por inteiro e também uma abordagem mais criativa do conteúdo trabalhado" A7; "permitiu o embasamento teórico envolvendo prática de escrita" A57; "criar memória e recordações de todo trajeto percorrido" A2; "Experiência construtiva, ensina a respeitar diferentes pontos de vista. A8.

Dentro dos pontos negativos apontados pelos alunos, o pouco tempo para realizá-lo, muita informação para colocar, depender do interesse dos outros colegas para construir o portfólio, dificuldades para analisar e escolher os fatos importantes. "Falta de tempo e muitas horas de dedicação" A14; “conseguir reunir todo o grupo” A36.

Em geral, o portfólio foi um instrumento que possibilitou o exercício da reflexão, o envolvimento de todos, visualização de todo o processo desenvolvido, ajudou a desenvolver habilidades de organização, cuidado com os detalhes, rever a prática, associar a teoria na prática, utilizar os conteúdos como recurso para a fundamentação do trabalho. Como instrumento de avaliação, foi importante porque permitiu avaliar todo o processo de aprendizagem e o cumprimento dos objetivos propostos no início da disciplina. Consideramos que a experiência foi válida, bastante trabalhosa, mas no final muito significativa.

Nas atividades da disciplina de Educação em Saúde, os alunos tiveram dificuldade em se perceberem como educadores em saúde e planejaram uma atividade totalmente técnica própria de sua formação (nutrição e esporte), não conseguiram realizar atividades fora da sua área de formação, o que gerou uma dificuldade em relação à valorização que fizeram da proposta da disciplina, por considerarem que a professora, desta disciplina, não poderia supervisioná-los por não ser da área de formação. Esta dificuldade ficou refletida na elaboração do portfólio. Este é um fato que a área da Saúde Coletiva vem vivenciando já algum tempo, onde as áreas especificas de formação apontam estes conteúdos como irrelevantes na prática dos futuros 
profissionais, ai aparece sempre um questionamento dos alunos, por que manter disciplinas da área de Saúde Coletiva, se não vão ser utilizadas no futuro, o que necessariamente interfere na disposição, envolvimento e comportamento dos alunos e este questionamento aumenta quando propomos atividades mais ativas que demandam mais envolvimento por parte dos alunos e que os obriga a desenvolver criatividade, a discutirem suas ideias e solicitam deles maior tempo.

O maior desafio vivenciado com esta estratégia foi orientar e conseguir que os alunos aderissem à proposta, se envolvessem e se apropriarem dela. Também reconhecemos a falta de experiência com o instrumento, o que foi um grande desafio, ao mesmo tempo, os portfólios elaborados por alguns alunos ajudaram a valorizar mais o instrumento e com certeza podemos afirmar que, hoje temos mais elementos para a orientação e acompanhamento da sua elaboração.

\section{Conclusões}

Cabe apontar que as estratégias utilizadas na sala de aula para a discussão dos conteúdos permitiram um envolvimento dos alunos na maioria dos encontros. Os alunos da disciplina Saúde Coletiva apresentaram um maior envolvimento na discussão dos conceitos e na participação das diversas atividades, em relação aos alunos da disciplina Educação em Saúde, foi difícil o envolvimento, desde o início da prática mostraram-se resistentes e pouco colaborativos para as atividades de supervisão. Em relação à atividade do portfólio, percebemos que ainda é um instrumento que ficou como uma tarefa, a ser elaborada como um trabalho final, cansativa e segundo alguns deles desnecessária.

No entanto, nas avaliações dos alunos foi possível, identificar pontos fortes e frágeis do instrumento para serem melhorados, assim como, confirmar a efetividade de seu uso dentro da sala de aula. Podemos afirmar, sem dúvida, que a atividade do portfólio foi um momento que, mesmo difícil, promoveu a reflexão tanto individual como coletiva, o que para nós foi um fator bastante relevante, considerando as atividades rotineiras na sala de aula. Mostrou que, em atividades diferenciadas precisamos cuidar das resistências diante metodologias novas, que de alguma forma desacomodam e incomodam tanto aos alunos como a nós professores. Possivelmente, esta atividade junto com as que a antecederam, possam ser referenciadas e justificadas 
como elementos que permitiram a transformação dos participantes e possam contribuir de alguma forma com a formação de profissionais mais reflexivos e atuantes.

Conforme apontado, a forma como exercemos nossa prática depende do que somos como seres individuais. Assim como, a disponibilidade que o professor tem para aprender, mudar e aderir a novas formas de pensar e agir, depende da forma como compreende seu papel de educador, sem medo de deixar de ser referência para seus alunos. Se cada docente produz sua própria forma de ser professor de acordo com as demandas surgidas na sala de aula, que está estratégia mesmo intuitiva e tímida, seja mais uma intenção de mudança.

\section{REFERÊNCIAS}

ALVARENGA, G. M.; ARAÚJO, Z. R. Portfólio: conceitos básicos e indicações para sua utilização. Estudos em avaliação educacional, v.17, n.33, jan/abr, 2006.

CASTANHO, M. E. Professores de Ensino Superior da área da Saúde e sua Prática Pedagógica, Interface - Comunicação, Saúde, Educação, v.6, n.10, 2002, p.51-62.

BORGES, D. S.; TAUCHEN, G. T. Inovação no Ensino Universitário: Propostas e cenários. Anpaedsul. Seminários de pesquisa em educação na região sul, 2012.

CYRINO, E. G.; TORALLES-PEREIRA, M. L. Trabalhando com estratégias de ensino-aprendizado por descoberta na área da saúde: a problematização e a aprendizagem baseada em problemas. Cad. Saúde Pública, Rio de Janeiro, 20(3):780788, mai-jun/2006.

BEHRENS, M. A. A prática pedagógica e o desafio do paradigma emergente. R. Bras. Est. Pedag., Brasília, v. 80, n. 196, p. 383-403, set./dez, 1999.

CHUN, R. Y. S.; BAHIA, M. M. O uso do Portfólio na formação em fonoaudiologia sob o eixo da integralidade. Revista CEFAC, out-dez/2006, 11(4):688-694.

FREIRE, P. Pedagogia da autonomia: saberes necessários à prática educativa. $7^{\mathrm{a}}$. ed. São Paulo: Paz e Terra, 1998.

FREIRE, P. Educação e mudança. Comunicação. v. 1. 29ª ed. Rio de Janeiro: Paz e Terra, 1996. (Coleção Educação).

MASETTO, M. Inovação na Educação Superior. Interface (Botucatu), Botucatu, v.8, n.14, p.197-202, feb/2006.

RANGEL, J. N. M. O portfólio e a avaliação no Ensino Superior. Estudos em avaliação Educacional, n.28, jul-dez/2003. 
RODRIGUES, M. F. de C. C. C. Portfólio: Estratégia formativa e de reflexão na formação inicial em educação de infância. Mestrado em Ciências da Educação. Universidade de Lisboa, Faculdade de Psicologia e Ciências da Educação. Dissertação. 2009.

ROGERS, C. Sobre o poder pessoal. $4^{\mathrm{a}}$ ed. São Paulo: Martins Fontes, 2001.

ROGERS, C. Liberdade de aprender em nossa década. $2^{a}$ ed. Porto Alegre: Artes médicas, 1986.

TANJI, S.; DANTAS da SILVA, C. M. S. L. M. As potencialidades e fragilidades do portfólio reflexivo na visão dos estudantes de enfermagem. Rev. Enferm, UERJ, Rio de Janeiro, jul-set/2008, (3):392-8.

VIEIRA, M. L.; DE SORDI, M. R. L. Possibilidades e Limites do uso do portfólio no trabalho pedagógico no ensino superior. Revista e-curriculum, São Paulo, v.8 n.1 abril 2012.

VILLAS BOAS, B. M. de F. Portfólio, avaliação e trabalho pedagógico. Campinas: Papirus, 2008.

\section{Como referenciar este artigo}

FUENTES-ROJAS, Marta. O portfólio como uma estratégia de aprendizagem na formação dos profissionais de saúde. Temas em Educ. e Saúde, Araraquara, v.13, n.1, p. 59-73, jan./jun. 2017. DOI <https://doi.org/10.26673/rtes.v13.n1.janjun2017.5.9607>. ISSN: 1517-7947.

Submetido em: 26/03/2017

Aprovado em: 20/08/2017 